\title{
Role of peroxisome proliferator-activated receptors in osteoarthritis (Review)
}

\author{
GANG HUANG $^{1,2^{*}}$, WEI JIANG ${ }^{3 *}$, WEIYONG XIE ${ }^{1}$, WEI LU ${ }^{2,4-6}$, WEIMIN ZHU ${ }^{2,4-6}$ and ZHENHAN DENG ${ }^{2,4-6}$ \\ ${ }^{1}$ Department of Sports Medicine, Orthopedic Hospital of Longgang, Shenzhen, Guangdong 518116; \\ ${ }^{2}$ Department of Sports Medicine, Shenzhen Second People's Hospital/The First Affiliated Hospital of Shenzhen University \\ Health Science Center, Shenzhen, Guangdong 518035; ${ }^{3}$ Bone and Joint Department, Shenzhen People's Hospital, \\ The Second Clinical Medical College of Jinan University and The First Affiliated Hospital of Southern University of \\ Science and Technology, Shenzhen, Guangdong 518020; ${ }^{4}$ School of Medicine, Shenzhen University, Shenzhen, \\ Guangdong 518035; ${ }^{5}$ School of Medicine, Guangzhou Medical University, Guangzhou, Guangdong 510182; \\ ${ }^{6}$ Key Laboratory of Tissue Engineering of Shenzhen, Shenzhen Second People's Hospital/The First Affiliated \\ Hospital of Shenzhen University Health Science Center, Shenzhen, Guangdong 518035, P.R. China
}

Received July 17, 2020; Accepted November 9, 2020

DOI: $10.3892 / \mathrm{mmr} .2020 .11798$

\begin{abstract}
Osteoarthritis (OA) is the most common form of arthritis, for which treatment options are not always satisfactory, since complete cure for OA is not yet possible. A better understanding of OA pathogenesis is thus important. The peroxisome proliferator-activated receptor (PPAR) plays a major regulatory role in lipid metabolism and energy homeostasis. This review article aimed to discuss the biological function of PPARs, and their role in regulating OA progression, as well as the therapeutic aspect of PPARs in OA. Studies indicate that PPARs regulate articular cartilage homeostasis through the modulation of various signaling pathways, and reduce the inflammatory responses in human OA cartilage. Furthermore, the deficiency of PPARs in the articular cartilage might be responsible for the acceleration of severe OA by increasing catabolic activity and suppression of chondroprotection. Therapeutic applications of PPAR-agonists can thus reduce the development of cartilage lesions by inhibiting the synthesis of various catabolic and inflammatory factors involved in the pathogenesis of OA. PPARs are thus important proteins in OA regulation, which may have significant importance in OA therapeutics.
\end{abstract}

Correspondence to: Dr Zhenhan Deng, Department of Sports Medicine, Shenzhen Second People's Hospital/The First Affiliated Hospital of Shenzhen University Health Science Center, 3002 Sungang West Road, Shenzhen, Guangdong 518035, P.R. China E-mail: dengzhenhan@email.szu.edu.cn

\section{*Contributed equally}

Key words: osteoarthritis, peroxisome proliferator-activated receptor, chondroprotection, inflammatory responses, peroxisome proliferator-activated receptor agonists

\section{Contents}

1. Introduction

2. Basic structure and function of PPARs

3. Role of PPARs in disease pathogenesis

4. PPARs in OA

5. Therapeutic aspect of PPARs in OA

6. Future research

7. Conclusion

\section{Introduction}

Osteoarthritis (OA) is the most common form of arthritis. OA is mainly characterized by the loss of structure in the articular cartilage, remodeling of the subchondral bone and osteophyte formation $(1,2)$. According to a review in 2017, OA has been reported to affect 240 million individuals worldwide (3). The etiology of OA is multifarious, including age, sex, genetic, mechanical stress on the joint, and loss of functional integrity of cellular organelles $(4,5)$. Treatment options of OA have expanded and their availability has greatly been improved. However, these treatments are not always satisfactory, since a complete cure for OA is not yet possible $(6,7)$. Therefore, there is a large demand for alternative therapeutics for OA. A better understanding of the underlying mechanisms of OA pathogenesis may facilitate the discover of more crucial targets, and may reduce the effect the devastating symptoms of OA $(8,9)$.

Currently, the role of proteins associated with lipid metabolism have been identified in health and disease. Among these proteins, peroxisome proliferator-activated receptor (PPAR) has been reported to be involved in reducing inflammatory responses in human OA cartilage (10-12). PPAR is a ligand-activated transcription factor and a member of the nuclear receptor superfamily. It is originally identified to play a key role in lipid homeostasis. There are three isotypes of PPAR: $\alpha, \gamma$ and $\beta / \delta(13,14)$. PPAR $\alpha$ is present in a wide range of cells including endothelial cells, hepatocytes, myocardiocytes 
and chondrocytes, and exerts anti-inflammatory effects on various tissues $(15,16)$. PPAR $\gamma$ has potent anti-inflammatory properties and regulates energy storage $(17,18)$. PPAR $\delta$ is the most widely expressed in whole body tissues, and regulates energy expenditure in cells $(19,20)$.

The present review discusses the association between PPAR and OA, as well as evaluating the protective effects of PPAR on the prevention of OA.

\section{Basic structure and function of PPARs}

PPARs were originally identified in Xenopus frogs by Isseman and Green in 1990 (21). PPARs are similar to steroid or thyroid hormone receptor, and contain four major functional domains: $\mathrm{N}$-terminal ligand-independent transactivation domain; DNA binding domain; co-factor docking domain; and C-terminal ligand-dependent transactivation domain. All isotypes of PPAR share a high degree of structural homology, particularly in the DNA-binding domain and ligand- and cofactor-binding domain $(22,23)$. Fig. 1 represents the schematic representation of the basic mechanism of PPARs.

PPARs heterodimerize with the retinoid $\mathrm{X}$ receptor (RXR) and bind to specific regions on the DNA termed peroxisome proliferators response elements (PPREs). The DNA consensus sequence of PPRE is 5'-AGGTCANAGGTCA-3', which occurs in the promoter region of target genes. The function of PPAR/RXR heterodimers is modified by a number of coregulator complexes, which leads to transactivation and transrepression of various genes, for example, cytokine genes or glucocorticoid response element-driven genes (24-26). When activated by a ligand, the PPAR/RXR heterodimer is associated with coactivator protein complexes (such as cAMP response element-binding protein, PPARs coactivators, cAMP response element-binding protein binding protein, and steroid receptor coactivator-1), and the rate of is transcription of target genes is increased $(27,28)$. In the absence of ligands, the PPAR/RXR heterodimer is associated with corepressor complexes (such as nuclear receptor co-repressor, and silencing mediator of retinoid acid and thyroid hormone receptor) and represses gene transcription by chromatin remodeling $(27,29)$. It was reported that activated PPAR/RXR heterodimer may also repress target gene transcription through DNA-independent protein-protein interactions with other transcription factors or coactivators $(30,31)$.

For the activation of PPARs, a number of natural or synthetic PPAR ligands, named agonists, have been identified. The mostwell-studied natural PPAR ligands include polyunsaturated fatty acids, eicosanoids, endocannabinoids and endogenous specialized pro-resolving mediators. The synthetic PPAR ligands include fibrates and thiazolidinediones $(32,33)$. PPAR antagonists could also be used as an interesting PPAR modulator. Antagonists are compounds that bind to the LBD but interfere with $\mathrm{H} 12$ folding, which inhibits the binding of co-activators or subsequent transcriptional activation. Several antagonists have been identified including MK886, GW6471, BADGE, GW9662, PD068235, SR-202, LG100641, indomethacin, GSK0660, SR13904 and NSC636948 (34).

PPARs play a critical role in regulating diverse biological processes such as development, differentiation, inflammation and wound healing. They also may act as lipid sensors and regulators of energy (lipid and carbohydrate) metabolism $(28,35)$.
However, PPARs may cause the metabolic energy imbalance in disease conditions such as inflammation, diabetes, obesity, dyslipidemia, neurodegenerative disorder and cancer $(20,36,37)$.

\section{Role of PPARs in disease pathogenesis}

PPARs play a major regulatory role in lipid metabolism and energy homeostasis by modulating target genes encoding lipid metabolism enzymes or lipid transporters, triggering a conformational change $(38,39)$. Activated PPARs are known to have the protective and detrimental effect against various types of diseases, including diabetes, dyslipidemia, inflammation, pain, obesity, cancer and neurodegenerative disorders $(40,41)$. PPARs play an important role in the immune response by inhibiting the expression of pro-inflammatory genes by peripheral immune cells through trans-repressive mechanisms. Several factors have been involved in regulating inflammatory signaling pathways mediated by different PPARs. During the inflammatory reaction, PPARs promote the inactivation of NF- $\kappa \mathrm{B}$. Activation of all PPARs by different pro-inflammatory factors causes the inhibition of NF- $\kappa \mathrm{B}$ activation, which leads to the inhibition of inflammatory reactions. Activated PPARs bind with and thus inactivate $\mathrm{p} 65 \mathrm{NF}-\mathrm{\kappa B}$ through the proteolytic degradation of p65 NF- $\kappa \mathrm{B}$, leading to the reduction of the pro-inflammatory response. PPAR $\alpha$ and PPAR $\gamma$ can inhibit the acetylation of p65 $\mathrm{NF}-\kappa \mathrm{B}$ by binding with $\mathrm{p} 300$ and inhibits activation of this pro-inflammatory factor. PPAR $\alpha$ and PPAR $\gamma$ can also inhibit $\mathrm{NF}-\kappa \mathrm{B}$ activation by increasing the expression of $\mathrm{I} \kappa \mathrm{B} \alpha$ and the activity of SIRT1. Activated PPAR $\beta / \delta$ inactivates NF- $\kappa \mathrm{B}$ p65 by disrupting the assembly of TAK1, TAB1 and HSP27 into a complex. PPAR $\gamma$ increases the activity of the E3 ubiquitin ligase, which leads to proteolytic degradation of $\mathrm{NF}-\kappa \mathrm{B}(42-44)$. PPARs also cause the inhibition of inflammatory reactions by inactivating STATs. Activated PPAR $\alpha$ disrupts the activity of STAT1 and PPAR- $\gamma$ blocks the pro-inflammatory action of IFN- $\gamma$, as well as increase the expression of the suppressor of cytokine signaling 3, by inhibiting the JAK-STAT pathway (45).

PPARs also inhibit the proliferation of several types of human cancer cell lines $(46,47)$. PPARs control the expression of genes involved in differentiation, and negatively regulates the cell cycle. PPARs have also shown efficacy in neurodegenerative disorders by inhibiting the activation of microglial cells $(20,48)$. $\mathrm{Fu}$ et al (49) reported that PPAR $\alpha$ has a protective role in obesity by initiating the transcription of proteins involved in lipid metabolism and repressing inducible nitric oxide synthase to repress feeding stimulation. Michalik et al (50) reported that PPAR $\alpha$ plays a role in wound healing by controlling inflammation at the wound site. Lee et al (51) demonstrated that activation of PPAR $\alpha$ regulated hepatic autophagy by nutrient status. Lee et al (52) showed that activation of PPAR $\alpha$ synergizes with the glucocorticoid receptor (GR) to promote self-renewal of early committed erythroid progenitors.

\section{PPARs in OA}

Mitochondrial dysfunction plays an important role in the initiation and progression of cartilage degeneration in OA by impairing chondrocyte growth, increasing chondrocyte oxidative stress and enhancing inflammatory responses $(53,54)$. PPARs have been implicated in regulating articular cartilage homeostasis through 


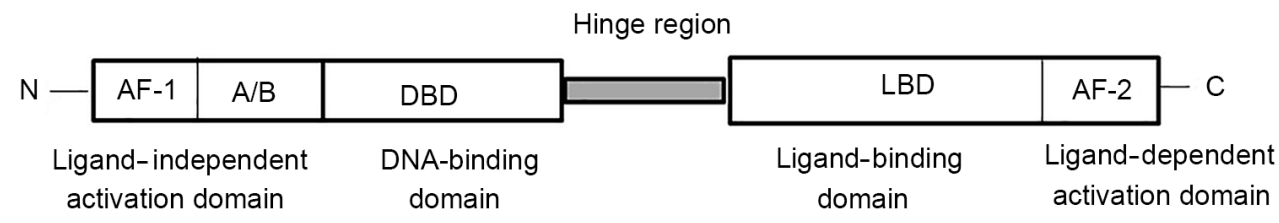

PPAR domain

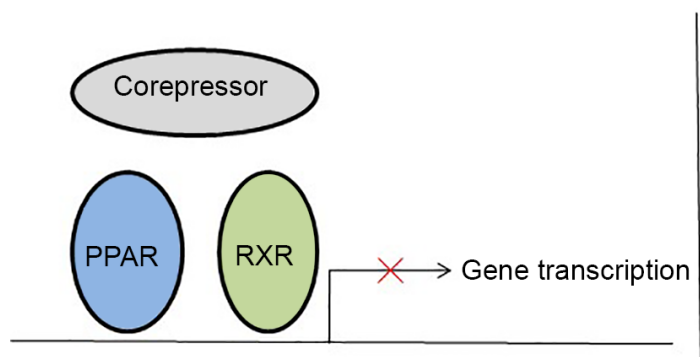

Ligand absent

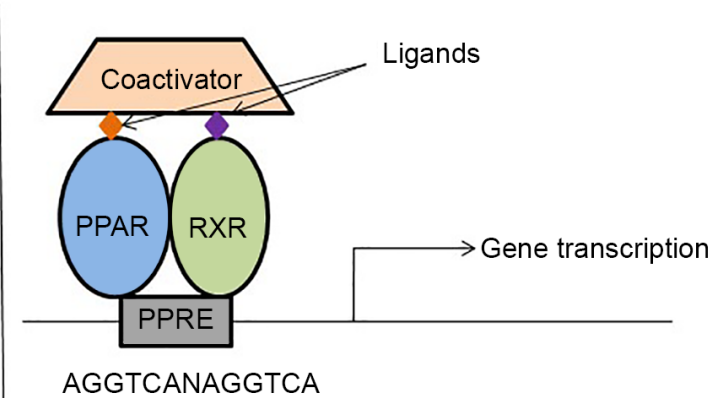

Ligand present

Figure 1. Basic mechanism of PPARs. PPARs heterodimerize with RXR and bind to PPREs. When activated by a ligand, the PPAR/RXR heterodimer is associated with coactivator protein complexes and the rate of transcription of target genes is increased. In the absence of ligands, the PPAR/RXR heterodimer is associated with corepressor complexes and gene transcription is repressed by chromatin remodeling. PPARs, peroxisome proliferator-activated receptors; RXR, retinoid X receptor; PPREs, peroxisome proliferators response elements.

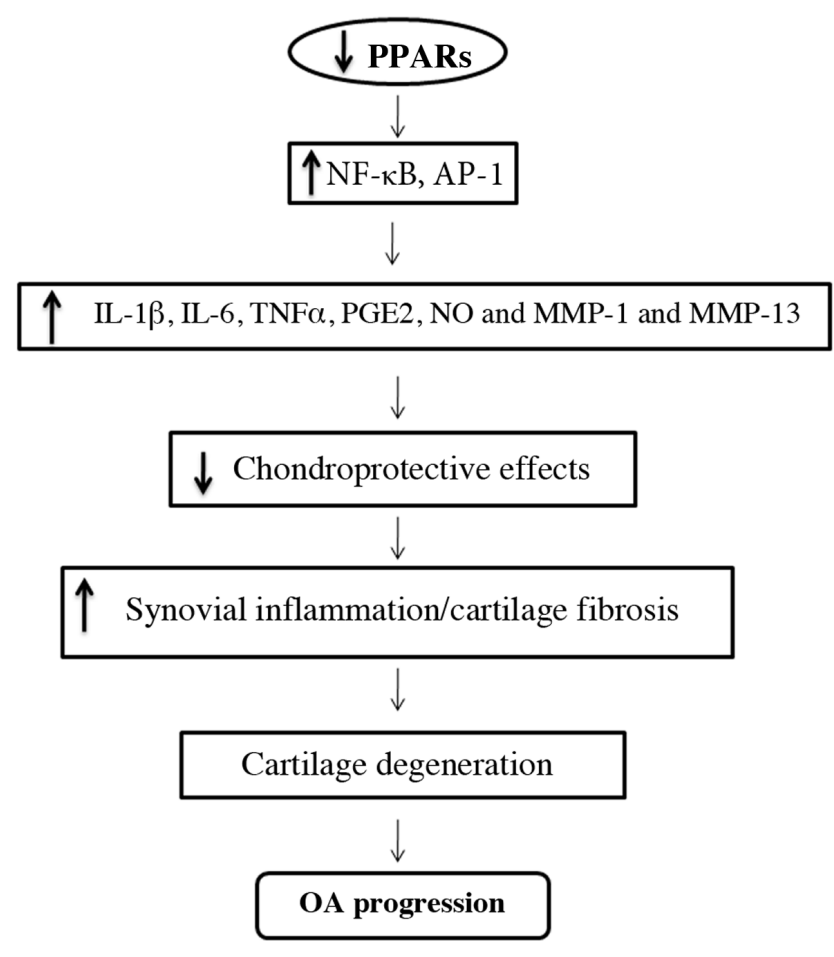

Figure 2. Mechanism of action of reduced level of PPARs in the progression of OA. The loss of PPARs can enhance the synthesis of various catabolic and inflammatory factors and reduces chondroprotective effects. Suppression of chondroprotection results in increased synovial inflammation and cartilage fibrosis, which could be a contributing factor in cartilage destruction and the progression of OA. PPARs, peroxisome proliferator-activated receptors; OA, osteoarthritis; IL, interleukin; TNF, tumor necrosis factor; PGE2, prostaglandin E2; NO, nitric oxide; MMP, matrix metalloprotease. the modulation of various signaling pathway. The reduction of PPAR $\alpha$ may promote inflammatory and destructive responses in OA cartilage. Loss of PPAR $\alpha$ increases the expression of MMP1 and MMP13, as well as enhances the production of triglycerides and cholesterol levels in plasma, and thereby induces cartilage degradation in OA. PPAR $\delta$ can act as a promoter of cartilage degeneration in $\mathrm{O}$ (55). Ratneswaran et al (56) reported that PPARd activation by GW501516 (a selective PPAR $\delta$ agonist) resulted in enhanced expression of several proteases in chondrocytes, increased aggrecan degradation and glycosaminoglycan release; whereas cartilage-specific PPAR $\delta$-knockout mice showed strong protection from cartilage degeneration in a mouse model of posttraumatic OA.

The deficiency of PPAR $\gamma$ in the articular cartilage may be responsible for the acceleration of severe OA by increasing catabolic activity and the suppression of chondroprotection (Fig. 2) (57,58). Wang et al (59) reported that PPAR- $\gamma$ coactivator (PGC)-1 $\alpha$ is the master regulator of mitochondrial biogenesis that critically mediates anti-catabolic activity in chondrocytes. Mitochondrial biogenesis has been impaired in human OA chondrocytes that promote chondrocyte pro-catabolic responses. PPAR $\gamma$ was also reported as a master adipogenic regulator that may influence the deposition of fat in both skeletal muscle and connective tissues. Deposition of fat is a strong risk factor for OA in the knee. The major adipose tissue in knee joint is infrapatellar fat pad (IPFP) that can produce inflammatory cytokines and adipokines. Consequently, PPAR $\gamma$ may associate with the pathological changes of IPFP in OA by triggering adipogenesis, via the activation of different signaling pathways (60-63). It is also reported that loss of PPAR $\gamma$ can enhance 
Table I. Therapeutic agents targeting PPARs for the treatment of OA.

\begin{tabular}{|c|c|c|c|c|c|}
\hline Authors & $\begin{array}{l}\text { Isotype } \\
\text { of PPAR }\end{array}$ & $\begin{array}{l}\text { Therapeutic } \\
\text { agents }\end{array}$ & $\begin{array}{l}\text { Experimental } \\
\text { sample }\end{array}$ & Effects & (Refs) \\
\hline $\begin{array}{l}\text { Clockaerts } \\
\text { et al, } 2011\end{array}$ & $\operatorname{PPAR} \alpha$ & $\begin{array}{l}\text { Wy-14643 } \\
\text { (PPAR } \alpha \text { agonist) }\end{array}$ & $\begin{array}{l}\text { Human OA } \\
\text { cartilage }\end{array}$ & $\begin{array}{l}\text { Anti-inflammatory and } \\
\text { anti-destructive effects. }\end{array}$ & $(55)$ \\
\hline $\begin{array}{l}\text { François } \\
\text { et al, } 2006\end{array}$ & $\operatorname{PPAR} \alpha$ & $\begin{array}{l}\text { Clofibrate } \\
\text { (PPAR } \alpha \text { agonist) }\end{array}$ & $\begin{array}{l}\text { Rabbit articular } \\
\text { chondrocytes }\end{array}$ & $\begin{array}{l}\text { Counteracts IL-1 } \beta \text {-induced MMP-1, } \\
\text { MMP- } 3 \text { and MMP- } 13 \text { production. }\end{array}$ & (15) \\
\hline $\begin{array}{l}\text { Vasheghani } \\
\text { et al, } 2015\end{array}$ & $\operatorname{PPAR} \gamma$ & $\begin{array}{l}\operatorname{PPAR} \gamma \\
\text { expression } \\
\text { vector }\end{array}$ & $\begin{array}{l}\text { Cartilage-specific } \\
\text { PPAR } \gamma \\
\text { KO mice }\end{array}$ & $\begin{array}{l}\text { Reduces mTOR expression, } \\
\text { increases expression of autophagy } \\
\text { markers and suppresses the expression } \\
\text { of OA inflammatory/ catabolic factors. }\end{array}$ & $(58)$ \\
\hline $\begin{array}{l}\text { Monemdjou } \\
\text { et al, } 2012\end{array}$ & $\operatorname{PPAR} \gamma$ & $\operatorname{PPAR} \gamma$ agonist & $\begin{array}{l}\text { Cartilage-specific } \\
\text { PPAR } \gamma \\
\text { KO mice }\end{array}$ & $\begin{array}{l}\text { Decreases cartilage degradation, } \\
\text { synovial inflammation, cartilage } \\
\text { fibrosis and decreases expression } \\
\text { of catabolic factors. }\end{array}$ & (12) \\
\hline $\begin{array}{l}\text { Fahmi } \\
\text { et al, } 2011\end{array}$ & $\operatorname{PPAR} \gamma$ & $\operatorname{PPAR} \gamma$ agonist & OA animal model & $\begin{array}{l}\text { Inhibits inflammation and } \\
\text { decreases synthesis of } \\
\text { cartilage degradation products. }\end{array}$ & $(65)$ \\
\hline $\begin{array}{l}\text { Ratneswaran } \\
\text { et al, } 2015\end{array}$ & PPAR $\delta$ & PPAR $\delta$ inhibitor & PPAR $\delta-K O$ mice & Decreases cartilage degeneration. & $(56)$ \\
\hline Qu et al, 2017 & $\operatorname{PPAR} \gamma$ & Mangiferin & $\begin{array}{l}\text { Human OA } \\
\text { chondrocytes }\end{array}$ & $\begin{array}{l}\text { Inhibits IL- } 1 \beta \text {-induced } \\
\text { inflammatory response. }\end{array}$ & $(71)$ \\
\hline $\begin{array}{l}\text { Wang } \\
\text { et al, } 2018\end{array}$ & $\operatorname{PPAR} \gamma$ & Antarctic krill oil & OA mice & $\begin{array}{l}\text { Improves articular cartilage degeneration } \\
\text { via activating chondrocyte autophagy } \\
\text { and inhibiting apoptosis. }\end{array}$ & (72) \\
\hline $\begin{array}{l}\text { Wang } \\
\text { et al, } 2019\end{array}$ & $\operatorname{PPAR} \gamma$ & Galectin-3 & $\begin{array}{l}\text { Human OA } \\
\text { chondrocytes }\end{array}$ & $\begin{array}{l}\text { Increases anti-inflammatory } \\
\text { and antiapoptotic effect. }\end{array}$ & (73) \\
\hline $\begin{array}{l}\text { Jingbo } \\
\text { et al, } 2015\end{array}$ & $\operatorname{PPAR} \gamma$ & Betulinic acid & $\begin{array}{l}\text { Human OA } \\
\text { chondrocytes }\end{array}$ & $\begin{array}{l}\text { Inhibits IL-1 } \beta \text {-induced } \\
\text { inflammation. }\end{array}$ & (74) \\
\hline $\begin{array}{l}\text { Kang } \\
\text { et al, } 2017\end{array}$ & $\operatorname{PPAR} \gamma$ & Oleanolic acid & $\mathrm{db} / \mathrm{db}$ mice & $\begin{array}{l}\text { Prevents high-glucose-induced cartilage } \\
\text { degeneration, inhibits apoptosis and } \\
\text { decreases SOD2 protein degradation. }\end{array}$ & $(75)$ \\
\hline
\end{tabular}

PPARs, peroxisome proliferator-activated receptors; OA, osteoarthritis; KO, knockout; IL, interleukin; MMP, matrix metalloprotease; SOD, superoxide dismutase.

the synthesis of various catabolic and inflammatory factors, including inflammatory cytokines such as interleukin (IL)-1b, IL-6, tumor necrosis factor- $\alpha$, prostaglandin E2, nitric oxide (NO) and matrix metalloproteinases (MMPs) involved in the pathogenesis of OA $(64,65)$. Moreover, loss of PPAR $\gamma$ reduces chondroprotective effects, anti-inflammatory and antifibrogenic effects, resulting in increased synovial inflammation (accumulation of macrophages) and increased synovial and cartilage fibrosis; this could be a contributing factor resulting in cartilage destruction and the progression of OA $(57,66)$.

\section{Therapeutic aspect of PPARs in OA}

As we have already discussed that $\mathrm{OA}$ is a progressive degenerative joint disorder and the most common form of arthritis, it has become a socioeconomic and clinical concern. Traditional OA treatments are still unsatisfactory to stimu- late the regeneration of cartilage. PPARs play a critical role in regulating cartilage health, and the lack of PPARs leads to the degeneration of cartilage in OA $(12,67,68)$. Several studies have found that PPARs may be a therapeutic target to counteract the degradative mechanisms associated with OA (Table I) $(12,15,55,56,58,65,69-73)$. These studies have showed that PPAR agonists can reduce the development of cartilage lesions by inhibiting the synthesis of various catabolic and inflammatory factors involved in the pathogenesis of OA $(74,75)$.

Clockaerts et al (55) hypothesized that PPAR $\alpha$ activation leads to anti-inflammatory and anti-destructive effects in human OA cartilage. Cartilage explants obtained from patients with OA were cultured and Wy-14643 (a potent and selective PPAR $\alpha$ agonist) was added to the cultures. It was found that the addition of PPAR $\alpha$ agonist Wy-14643 inhibited the inflammatory and destructive responses in human OA cartilage explants 
by decreasing the mRNA expression of MMP1, MMP3 and MMP13 in cartilage explants, as well as decreasing the secretion of inflammatory marker NO in the culture medium of cartilage explants (55). François et al (15) demonstrated that the addition of clofibrate (another PPAR $\alpha$ agonist) counteracts IL-1 $\beta$ induced MMP1, MMP3 and MMP13 production in rabbit articular chondrocytes. Vasheghani et al (58) investigated the role of PPAR $\gamma$ in maintaining cartilage homeostasis and the specific in vivo role in OA pathophysiology. Inducible cartilage-specific PPAR $\gamma$ knockout (KO) mice were subjected to the de-stabilization of medial meniscus (DMM) model of OA. It was found that PPAR $\gamma \mathrm{KO}$ mice exhibit increased cartilage degradation, chondrocyte apoptosis and the overproduction of OA inflammatory/catabolic factors through aberrant mTOR signaling and the suppression of key autophagy markers in the articular cartilage (58). Furthermore, in vitro rescue experiments using PPAR $\gamma$ expression vector and in vivo studies using PPAR $\gamma$-mTOR double KO mice showed reversed phenotypes of PPAR $\gamma$ KO mice chondrocytes by reducing mTOR expression, increasing expression of autophagy markers and suppressing the expression of OA inflammatory/catabolic factors (58). Monemdjou et al (12) also reported that activation of PPAR $\gamma$ by its agonists can decrease the development of cartilage lesions in OA animal models. Cartilage-specific PPAR $\gamma$ knockout (KO) mice were generated using the Cre-lox system, which exhibited reduced cartilage degradation, synovial inflammation, cartilage fibrosis and decreased expression of catabolic factors (12). Fahmi et al (65) also indicated that agonists of PPAR $\gamma$ decreased the development and progression of cartilage lesions in OA animal models by inhibiting inflammation and reducing the synthesis of cartilage degradation products.

Ratneswaran et al (56) reported that PPARS potentially have opposing roles in OA development, with PPAR $\alpha$ and PPAR $\gamma$ acting in a protective manner and PPAR $\delta$ in a degenerative manner. The role of PPAR $\delta$ as a promoter of cartilage degeneration was examined in a mouse model of posttraumatic OA and suggested that pharmacologic inhibition of PPARS is a promising therapeutic strategy for the treatment of OA. They treated mouse chondrocytes and knee explants with a pharmacologic agonist of PPARS (GW501516) and evaluated that PPAR $\delta$ activation by GW501516, resulting in increased expression of several proteases in chondrocytes, as well as aggrecan degradation and glycosaminoglycan release in knee joint explants (56). In the in vivo study, PPAR $\delta$ was deleted from the cartilage of mice and found that cartilage-specific PPARS-KO mice showed strong protection in the DMM model against posttraumatic OA from cartilage degeneration (56).

Several other studies focused on naturally occurring plant products that may activate PPARs and provide a preventive strategy for the treatment of OA. Qu et al (71) investigated the role of mangiferin (MFN) in human OA chondrocytes. Cells were treated with various concentrations of MFN and found that MFN inhibited IL-1 $\beta$-induced inflammatory response in human OA chondrocytes by activating PPAR $\gamma$ (71). Wang et al (72) suggested that Antarctic krill oil (AKO) improves articular cartilage degeneration via activating chondrocyte autophagy and inhibiting apoptosis in mice with OA. It was also shown that AKO upregulates PPAR $\gamma$ and reduces mTOR signaling, and thereby maintains cartilage homeostasis in OA model mouse (72). Wang et al (73) reported that the downregulation of galectin-3 (Gal-3) protects from lipopolysaccharide-induced chondrocytes injury in OA via the regulation of TLR4 and PPAR $\gamma$-mediated NF- $\kappa$ B signaling pathway. This indicated that the activation of PPAR $\gamma$ effectively increases anti-inflammatory and antiapoptotic effect in human OA chondrocytes, through the depletion of Gal-3 (73). Jingbo et al (74) investigated the protective effect of betulinic acid (BA; a triterpenoid isolated from birch bark) against OA progression. It was suggested that BA inhibited IL-1 $\beta$-induced inflammation in OA chondrocytes by activating PPAR $\gamma(74)$. Kang et al (75) reported that hyperglycemia-induced cartilage degeneration induces $\mathrm{OA}$. It was suggested that oleanolic acid (OLA) prevents high-glucose-induced cartilage degeneration via PPAR $\gamma$-associated mitochondrial stabilization. It was also reported that OLA treatment inhibited apoptosis and decreased SOD2 protein degradation via PPAR $\gamma(75)$.

\section{Future research}

OA is the most prevalent chronic human health disorder that is characterized by cartilage degeneration. It is a leading cause of disability, which reduces mobility and increases dependency $(76,77)$. Due to the lack of PPARs playing a critical role in the pathogenesis of OA, the activation of PPARs using PPAR agonists may be interesting therapeutic targets for the prevention of OA progression $(78,79)$. Investigation of novel physiological roles of PPARs and the identification of specific PPAR agonists, which reduce the risk of OA by limiting cartilage degeneration, may provide exciting therapeutic strategies in the future. Moreover, the precise molecular mechanisms through which PPARs exert their actions require clarification. For example, the detailed signal transduction mechanism from ligand binding (PPAR-agonists) to gene transcription should be clarified. In addition, clinical investigations on PPAR activation in patients with OA should be performed for the establishment of this therapeutic approach.

\section{Conclusion}

OA is a slowly progressive disease that is becoming a worldwide epidemic. Early identification and administration of effective treatment, to inhibit the destructive or inflammatory responses in cartilage, may be the best strategies against OA. A better understanding of the pathogenic mechanisms may provide the knowledge to identify new targets to develop therapeutic drugs for OA. PPARs are affected in OA and targeting PPARs might be an innovative approach for the treatment of OA. The use of selective targets of PPARs may minimize the side effects and might be a promising therapeutic avenue for the treatment of OA. More studies are necessary to identify selective agonists for efficiently targeting PPARs in the prevention and treatment of OA.

\section{Acknowledgements}

Not applicable.

\section{Funding}

The present study was supported by the National Natural Science Foundation of China (grant no. 81902303), the 
Guangdong Basic and Applied Basic Research Foundation (grant no. 2020A151501048), the Shenzhen Science and Technology Project (grant nos. JCYJ20190806164216661, GJHZ20180416164801042 and JCYJ20180305124912336) and the Clinical Research Project of Shezhen Second People's Hospital (grant no. 20203357028).

\section{Availability of data and materials}

Not applicable.

\section{Authors' contributions}

$\mathrm{ZD}$ and $\mathrm{GH}$ reviewed the design of the review, and drafted and proofread the article. WJ created the figures and revised the article. WX, WL and WZ participated in literature collection, analysis and summary. ZD supervised the project. All authors read and approved the final manuscript.

\section{Ethics approval and consent to participate}

Not applicable.

\section{Patient consent for publication}

Not applicable.

\section{Competing interests}

The authors declare that they have no competing interests.

\section{References}

1. Cucchiarini M, de Girolamo L, Filardo G, Oliveira JM, Orth P, Pape D and Reboul P: Basic science of osteoarthritis. J Exp Orthop 3: 22, 2016.

2. Hügle $\mathrm{T}$ and Geurts J: What drives osteoarthritis?-synovial versus subchondral bone pathology. Rheumatology (Oxford) 56 1461-1471, 2017.

3. Nelson AE: Osteoarthritis year in review 2017: Clinical. Osteoarthritis Cartilage 26: 319-325, 2018.

4. Xia B, Di Chen, Zhang J, Hu S, Jin H and Tong P: Osteoarthritis pathogenesis: A review of molecular mechanisms. Calcif Tissue Int 95: 495-505, 2014

5. Chen D, Shen J, Zhao W, Wang T, Han L, Hamilton JL and Im HJ: Osteoarthritis: Toward a comprehensive understanding of pathological mechanism. Bone Res 5: 16044, 2017.

6. Vargas Negrín F, Medina Abellán MD, Hermosa Hernán JC and de Felipe Medina R: Treatment of patients with osteoarthritis. Aten Primaria 46 (Suppl 1): 39-61, 2014 (In Spanish).

7. Sun MM, Beier F and Pest MA: Recent developments in emerging therapeutic targets of osteoarthritis. Curr Opin Rheumatol 29 96-102, 2017.

8. Chevalier X, Eymard F and Richette P: Biologic agents in osteoarthritis: Hopes and disappointments. Nat Rev Rheumatol 9: 400-410, 2013.

9. Mobasheri A and Batt M: An update on the pathophysiology of osteoarthritis. Ann Phys Rehabil Med 59: 333-339, 2016.

10. Wu J, Liu W, Bemis A, Wang E, Qiu Y, Morris EA, Flannery CR and Yang Z: Comparative proteomic characterization of articular cartilage tissue from normal donors and patients with osteoarthritis. Arthritis Rheum 56: 3675-3684, 2007.

11. Boileau C, Martel-Pelletier J, Fahmi H, Mineau F, Boily M and Pelletier JP: The peroxisome proliferator-activated receptor gamma agonist pioglitazone reduces the development of cartilage lesions in an experimental dog model of osteoarthritis: In vivo protective effects mediated through the inhibition of key signaling and catabolic pathways. Arthritis Rheum 56: 2288-2298, 2007.
12. Monemdjou R, Vasheghani F, Fahmi H, Perez G, Blati M, Taniguchi N, Lotz M, St-Arnaud R, Pelletier JP, Martel-Pelletier J, et al: Association of cartilage-specific deletion of peroxisome proliferator-activated receptor $\gamma$ with abnormal endochondral ossification and impaired cartilage growth and development in a murine model. Arthritis Rheum 64: 1551-1561, 2012.

13. Guan Y: Peroxisome proliferator-activated receptor family and its relationship to renal complications of the metabolic syndrome. J Am Soc Nephrol 15: 2801-2815, 2004.

14. Dubois V, Eeckhoute J, Lefebvre P and Staels B: Distinct but complementary contributions of PPAR isotypes to energy homeostasis. J Clin Invest 127: 1202-1214, 2017.

15. Francois M,Richette P,Tsagris L, Fitting C,Lemay C,Benallaoua M, Tahiri K and Corvol MT: Activation of the peroxisome proliferator-activated receptor alpha pathway potentiates interleukin-1 receptor antagonist production in cytokine-treated chondrocytes. Arthritis Rheum 54: 1233-1245, 2006.

16. Kono K, Kamijo Y,Hora K, Takahashi K,Higuchi M,Kiyosawa K, Shigematsu H, Gonzalez FJ and Aoyama T: PPAR\{alpha\} attenuates the proinflammatory response in activated mesangial cells. Am J Physiol Renal Physiol 296: F328-F336, 2009.

17. Sha W, Thompson K, South J, Baron M and Leask A: Loss of PPAR $\gamma$ expression by fibroblasts enhances dermal wound closure. Fibrogenesis Tissue Repair 5: 5, 2012.

18. Majdalawieh A and Ro HS: PPARgammal and LXRalpha face a new regulator of macrophage cholesterol homeostasis and inflammatory responsiveness, AEBP1. Nucl Recept Signal 8: e004, 2010

19. Tanaka T, Yamamoto J, Iwasaki S, Asaba H, Hamura H, Ikeda Y, Watanabe M, Magoori K, Ioka RX, Tachibana K, et al: Activation of peroxisome proliferator-activated receptor delta induces fatty acid beta-oxidation in skeletal muscle and attenuates metabolic syndrome. Proc Natl Acad Sci USA 100: 15924-15929, 2003.

20. Tyagi S, Gupta P, Saini AS, Kaushal C and Sharma S: The peroxisome proliferator-activated receptor: A family of nuclear receptors role in various diseases. J Adv Pharm Technol Res 2: 236-240, 2011.

21. Issemann I and Green S: Activation of a member of the steroid hormone receptor superfamily by peroxisome proliferators. Nature 347: 645-650, 1990.

22. Michalik L, Auwerx J, Berger JP, Chatterjee VK, Glass CK, Gonzalez FJ, Grimaldi PA, Kadowaki T, Lazar MA, O'Rahilly S, et al: International Union of Pharmacology. LXI. Peroxisome proliferator-activated receptors. Pharmacol Rev 58: 726-741, 2006.

23. Zoete V, Grosdidier A and Michielin O: Peroxisome proliferatoractivated receptor structures: Ligand specificity, molecular switch and interactions with regulators. Biochim Biophys Acta 1771: 915-925, 2007.

24. Guan Y and Breyer MD: Peroxisome proliferator-activated receptors (PPARs): Novel therapeutic targets in renal disease. Kidney Int 60: 14-30, 2001.

25. Michalik L and Wahli W: Involvement of PPAR nuclear receptors in tissue injury and wound repair. J Clin Invest 116: 598-606, 2006.

26. Bougarne N, Paumelle R, Caron S, Hennuyer N, Mansouri R, Gervois P, Staels B, Haegeman G and De Bosscher K: PPARalpha blocks glucocorticoid receptor alpha-mediated transactivation but cooperates with the activated glucocorticoid receptor alpha for transrepression on NF-kappaB. Proc Natl Acad Sci USA 106: 7397-7402, 2009

27. Qi C, Zhu Y and Reddy JK: Peroxisome proliferator-activated receptors, coactivators, and downstream targets. Cell Biochem Biophys 32: 187-204, 2000.

28. Yu S and Reddy JK: Transcription coactivators for peroxisome proliferator-activated receptors. Biochim Biophys Acta 1771: 936-951, 2007.

29. Balakumar P, Rose M, Ganti SS, Krishan P and Singh M: PPAR dual agonists: Are they opening Pandora's Box? Pharmacol Res 56: 91-98, 2007.

30. Berger J and Moller DE: The mechanisms of action of PPARs. Annu Rev Med 53: 409-435, 2002.

31. Oliveira AC, Bertollo CM, Rocha LT, Nascimento EB Jr, Costa KA and Coelho MM: Antinociceptive and antiedematogenic activities of fenofibrate, an agonist of PPAR alpha, and pioglitazone, an agonist of PPAR gamma. Eur J Pharmacol 561: 194-201, 2007.

32. Kytikova OY, Perelman JM, Novgorodtseva TP, Denisenko YK, Kolosov VP, Antonyuk MV and Gvozdenko TA: Peroxisome Proliferator-Activated Receptors as a Therapeutic Target in Asthma. PPAR Res 2020: 8906968, 2020. 
33. Peraza MA, Burdick AD, Marin HE, Gonzalez FJ and Peters JM: The toxicology of ligands for peroxisome proliferator-activated receptors (PPAR). Toxicol Sci 90: 269-295, 2006.

34. Ammazzalorso A, De Filippis B, Giampietro L and Amoroso R: Blocking the peroxisome proliferator-activated receptor (PPAR): An overview. ChemMedChem 8: 1609-1616, 2013.

35. Ferré P: The biology of peroxisome proliferator-activated receptors: Relationship with lipid metabolism and insulin sensitivity. Diabetes 53 (Suppl 1): S43-S50, 2004.

36. Racke MK and Drew PD: PPARs in Neuroinflammation. PPAR Res 2008: 638356, 2008

37. Terauchi $\mathrm{Y}$ and Kadowaki T: PPAR and diabetes. Nihon Rinsho 63: 623-629, 2005 (In Japanese).

38. Fajas L,Debril MB and Auwerx J: Peroxisome proliferator-activated receptor-gamma: From adipogenesis to carcinogenesis. J Mol Endocrinol 27: 1-9, 2001

39. Gross B, Pawlak M, Lefebvre P and Staels B: PPARs in obesity-induced T2DM, dyslipidaemia and NAFLD. Nat Rev Endocrinol 13: 36-49, 2017.

40. Jones AB: Peroxisome proliferator-activated receptor (PPAR) modulators: Diabetes and beyond. Med Res Rev 21: 540-552, 2001.

41. Gurnell M, Savage DB, Chatterjee VK and O'Rahilly S: The metabolic syndrome: Peroxisome proliferator-activated receptor gamma and its therapeutic modulation. J Clin Endocrinol Metab 88: 2412-2421, 2003.

42. Korbecki J, Bobiński R and Dutka M: Self-regulation of the inflammatory response by peroxisome proliferator-activated receptors. Inflamm Res 68: 443-458, 2019.

43. Hou Y, Moreau F and Chadee K: PPAR $\gamma$ is an E3 ligase that induces the degradation of NFKB/p65. Nat Commun 3: 1300 , 2012.

44. Scirpo R, Fiorotto R, Villani A, Amenduni M, Spirli C and Strazzabosco M: Stimulation of nuclear receptor peroxisome proliferator-activated receptor- $\gamma$ limits NF- $\kappa \mathrm{B}$-dependent inflammation in mouse cystic fibrosis biliary epithelium. Hepatology 62: 1551-1562, 2015.

45. Wang S, Awad KS, Elinoff JM, Dougherty EJ, Ferreyra GA, Wang JY, Cai R, Sun J, Ptasinska A and Danner RL: $\mathrm{G}$ protein-coupled receptor 40 (GPR40) and peroxisome proliferator-activated receptor $\gamma$ (PPAR $\gamma)$ : An Integrated Two-Receptor Signaling Pathway. J Biol Chem 290: 19544-19557, 2015.

46. Badr MZ: PPAR research: Successful launching and promising future. PPAR Res 2009: 543584, 2009.

47. Colin C, Salamone S, Grillier-Vuissoz I, Boisbrun M, Kuntz S, Lecomte J, Chapleur Y and Flament S: New troglitazone derivatives devoid of PPAR $\gamma$ agonist activity display an increased antiproliferative effect in both hormone-dependent and hormone-independent breast cancer cell lines. Breast Cancer Res Treat 124: 101-110, 2010.

48. Grommes C, Landreth GE and Heneka MT: Antineoplastic effects of peroxisome proliferator-activated receptor gamma agonists. Lancet Oncol 5: 419-429, 2004.

49. Fu J, Gaetani S, Oveisi F, Lo Verme J, Serrano A, Rodríguez De Fonseca F, Rosengarth A, Luecke H, Di Giacomo B, Tarzia G, et al: Oleylethanolamide regulates feeding and body weight through activation of the nuclear receptor PPAR-alpha. Nature 425: 90-93, 2003.

50. Michalik L, Desvergne B, Tan NS, Basu-Modak S, Escher P, Rieusset J, Peters JM, Kaya G, Gonzalez FJ, Zakany J, et al: Impaired skin wound healing in peroxisome proliferator-activated receptor (PPAR)alpha and PPARbeta mutant mice. J Cell Biol 154: 799-814, 2001.

51. Lee HY, Gao X, Barrasa MI, Li H, Elmes RR, Peters LL and Lodish HF: PPAR- $\alpha$ and glucocorticoid receptor synergize to promote erythroid progenitor self-renewal. Nature 522: 474-477, 2015.

52. Lee JM, Wagner M, Xiao R, Kim KH, Feng D, Lazar MA and Moore DD: Nutrient-sensing nuclear receptors coordinate autophagy. Nature 516: 112-115, 2014.

53. Blanco FJ, Rego I and Ruiz-Romero C: The role of mitochondria in osteoarthritis. Nat Rev Rheumatol 7: 161-169, 2011.

54. Gavriilidis C, Miwa S, von Zglinicki T, Taylor RW and Young DA: Mitochondrial dysfunction in osteoarthritis is associated with down-regulation of superoxide dismutase 2. Arthritis Rheum 65: 378-387, 2013

55. Clockaerts S, Bastiaansen-Jenniskens YM, Feijt C, Verhaar JA, Somville J, De Clerck LS and Van Osch GJ: Peroxisome proliferator activated receptor alpha activation decreases inflammatory and destructive responses in osteoarthritic cartilage. Osteoarthritis Cartilage 19: 895-902, 2011.
56. Ratneswaran A, LeBlanc EA, Walser E, Welch I, Mort JS, Borradaile $\mathrm{N}$ and Beier F: Peroxisome proliferator-activated receptor $\delta$ promotes the progression of posttraumatic osteoarthritis in a mouse model. Arthritis Rheumatol 67: 454-464, 2015.

57. Vasheghani F,Monemdjou R, Fahmi H,Zhang Y,Perez G, Blati M, St-Arnaud R, Pelletier JP, Beier F, Martel-Pelletier J, et al: Adult cartilage-specific peroxisome proliferator-activated receptor gamma knockout mice exhibit the spontaneous osteoarthritis phenotype. Am J Pathol 182: 1099-1106, 2013.

58. Vasheghani F, Zhang Y, Li YH, Blati M, Fahmi H, Lussier B, Roughley P, Lagares D, Endisha H, Saffar B, et al: PPAR deficiency results in severe, accelerated osteoarthritis associated with aberrant mTOR signalling in the articular cartilage. Ann Rheum Dis 74: 569-578, 2015.

59. Wang Y, Zhao X, Lotz M, Terkeltaub R and Liu-Bryan R: Mitochondrial biogenesis is impaired in osteoarthritis chondrocytes but reversible via peroxisome proliferator-activated receptor $\gamma$ coactivator $1 \alpha$. Arthritis Rheumatol 67: 2141-2153, 2015.

60. Cordani N, Pisa V, Pozzi L, Sciorati C and Clementi E: Nitric oxide controls fat deposition in dystrophic skeletal muscle by regulating fibro-adipogenic precursor differentiation. Stem Cells 32: 874-885, 2014

61. Reggio A, Spada F, Rosina M, Massacci G, Zuccotti A, Fuoco C, Gargioli C, Castagnoli L and Cesareni G: The immunosuppressant drug azathioprine restrains adipogenesis of muscle Fibro/Adipogenic Progenitors from dystrophic mice by affecting AKT signaling. Sci Rep 9: 4360, 2019.

62. Cerquone Perpetuini A, Giuliani G, Reggio A, Cerretani M, Santoriello M, Stefanelli R, Palma A, Vumbaca S, Harper S, Castagnoli L, et al: Janus effect of glucocorticoids on differentiation of muscle fibro/adipogenic progenitors. Sci Rep 10: 5363 , 2020.

63. Reggio A, Rosina M,Palma A, Cerquone Perpetuini A, PetrilliLL, Gargioli C, Fuoco C, Micarelli E, Giuliani G, Cerretani M, et al: Adipogenesis of skeletal muscle fibro/adipogenic progenitors is affected by the WNT5a/GSK3/ $\beta$-catenin axis. Cell Death Differ 27: 2921-2941, 2020.

64. Boileau C, Martel-Pelletier J, Fahmi H, Mineau F, Boily M and Pelletier JP: The peroxisome proliferator-activated receptor gamma agonist pioglitazone reduces the development of cartilage lesions in an experimental dog model of osteoarthritis: In vivo protective effects mediated through the inhibition of key signaling and catabolic pathways. Arthritis Rheum 56: 2288-2298, 2007.

65. Fahmi H, Martel-Pelletier J,Pelletier JP and Kapoor M: Peroxisome proliferator-activated receptor gamma in osteoarthritis. Mod Rheumatol 21: 1-9, 2011.

66. Giaginis C, Giagini A and Theocharis S: Peroxisome proliferator-activated receptor-gamma (PPAR-gamma) ligands as potential therapeutic agents to treat arthritis. Pharmacol Res 60: 160-169, 2009.

67. Hellio Le Graverand-Gastineau MP: OA clinical trials: current targets and trials for OA. Choosing molecular targets: what have we learned and where we are headed? Osteoarthritis Cartilage 17: 1393-1401, 2009

68. Malemud CJ: Biologic basis of osteoarthritis: State of the evidence. Curr Opin Rheumatol 27: 289-294, 2015.

69. Kobayashi T, Notoya K, Naito T, Unno S, Nakamura A, Martel-Pelletier J and Pelletier JP: Pioglitazone, a peroxisome proliferator-activated receptor gamma agonist, reduces the progression of experimental osteoarthritis in guinea pigs. Arthritis Rheum 52: 479-487, 2005.

70. Afif H, Benderdour M, Mfuna-Endam L, Martel-Pelletier J, Pelletier JP, Duval N and Fahmi H: Peroxisome proliferator-activated receptor gammal expression is diminished in human osteoarthritic cartilage and is downregulated by interleukin-1beta in articular chondrocytes. Arthritis Res Ther 9: R31, 2007.

71. Qu Y, Zhou L and Wang C: Mangiferin inhibits IL-1 $\beta$-induced inflammatory response by activating PPAR- $\gamma$ in human osteoarthritis chondrocytes. Inflammation 40: 52-57, 2017.

72. Wang K, Han L, Zhu Y, Liu Y, Wang J and Xue C: Antarctic Krill Oil improves articular cartilage degeneration via activating chondrocyte autophagy and inhibiting apoptosis in osteoarthritis mice. J Funct Foods 46: 413-422, 2018.

73. Wang JS, Xiao WW, Zhong YS, Li XD, Du SX, Xie P, Zheng GZ and Han JM: Galectin-3 deficiency protects lipopolysaccharide-induced chondrocytes injury via regulation of TLR4 and PPAR- $\gamma$-mediated NF- $\mathrm{BB}$ signaling pathway. J Cell Biochem 120: 10195-10204, 2019. 
74. Jingbo W, Aimin C, Qi W, Xin L and Huaining L: Betulinic acid inhibits IL- $1 \beta$-induced inflammation by activating PPAR- $\gamma$ in human osteoarthritis chondrocytes. Int Immunopharmacol 29 : 687-692, 2015

75. Kang X, Yang Z, Sheng J, Liu JB, Xie QY, Zheng W and Chen K: Oleanolic acid prevents cartilage degeneration in diabetic mice via PPAR $\gamma$ associated mitochondrial stabilization. Biochem Biophys Res Commun 490: 834-840, 2017.

76. Karsdal MA, Michaelis M, Ladel C, Siebuhr AS, Bihlet AR, Andersen JR, Guehring H, Christiansen C, Bay-Jensen AC and Kraus VB: Disease-modifying treatments for osteoarthritis (DMOADs) of the knee and hip: Lessons learned from failures and opportunities for the future. Osteoarthritis Cartilage 24: 2013-2021, 2016.
77. Vitale ND, Vandenbulcke F, Chisari E, Iacono F, Lovato L, Di Matteo B and Kon E: Innovative regenerative medicine in the management of knee OA: The role of Autologous Protein Solution. J Clin Orthop Trauma 10: 49-52, 2019.

78. Stienstra R, Mandard S, Patsouris D, Maass C, Kersten S and Müller M: Peroxisome proliferator-activated receptor alpha protects against obesity-induced hepatic inflammation. Endocrinology 148: 2753-2763, 2007.

79. Zhou JL, Liu SQ, Qiu B, Hu QJ, Ming JH and Peng H: The protective effect of sodium hyaluronate on the cartilage of rabbit osteoarthritis by inhibiting peroxisome proliferator-activated receptor-gamma messenger RNA expression. Yonsei Med J 50: 832-837, 2009. 